\title{
The COX-2 promoter polymorphism -765 G >C is associated with early-onset, conventional and stump gastric cancers
}

\author{
Robert Sitarz ${ }^{1,2}$, Roos J Leguit ${ }^{1}$, Wendy WJ de Leng ${ }^{1}$, Mirjam Polak ${ }^{3}$, Folkert M Morsink ${ }^{1}$, \\ Onno Bakker ${ }^{4}$, Ryszard Maciejewski ${ }^{2}$, G Johan A Offerhaus ${ }^{1,3}$ and Anya N Milne ${ }^{1}$ \\ ${ }^{1}$ Department of Pathology, University Medical Centre, Utrecht, The Netherlands; ${ }^{2}$ Department of Human \\ Anatomy, Medical University of Lublin, Lublin, Poland; ${ }^{3}$ Department of Pathology, Academic Medical Centre, \\ Amsterdam, The Netherlands and ${ }^{4}$ Department of Endocrinology, Academic Medical Centre, Amsterdam, \\ The Netherlands
}

\begin{abstract}
COX-2 overexpression is known to be an important mechanism in gastric carcinogenesis. Previously we have found that early-onset gastric cancer has a unique COX-2 low-expressing phenotype that differs significantly from that of the frequent overexpression seen in conventional gastric cancers. To investigate whether the COX-2 -765 G > C promoter polymorphism (known to lead to a reduction of COX-2 promoter activity in the colon) may explain this difference in expression, we carried out single-nucleotide polymorphism (SNP) analysis of 241 gastric cancers, including early-onset gastric cancer, conventional gastric cancers and gastric stump cancers, as well as in 100 control patients, using real-time PCR and sequence analysis, and correlated these findings with COX-2 expression using immunohistochemistry. We found that the $\mathrm{C}$ allele was present in $30 \%$ of early-onset gastric cancers, $24 \%$ of conventional gastric cancer, $23 \%$ of stump cancers, in contrast to $41 \%$ in the control group. There was a statistically significant difference in the presence of the $\mathrm{C}$ allele in patients with gastric cancer compared with the control group $(P=0.007)$, with the $C$ allele being associated with protection against gastric cancer. However, there was no significant difference between the early-onset, conventional and stump gastric cancer groups. Interestingly, there was no correlation between the presence of the $\mathrm{C}$ allele and a difference in COX-2 expression. In summary, we show that the COX-2 -765 G allele promoter polymorphism is significantly associated with gastric cancer when compared with the normal control group, but does not appear to be related directly to COX-2 expression pattern in gastric cancer. Although early-onset gastric cancers appear to have a unique COX-2 expression pattern when compared with conventional gastric cancer, the exact mechanism by which this occurs is yet to be elucidated.
\end{abstract}

Modern Pathology (2008) 21, 685-690; doi:10.1038/modpathol.2008.36; published online 29 February 2008

Keywords: early-onset gastric cancer; COX-2; polymorphisms; gastric cancer

Gastric cancer is the second most common cause of cancer-related death in the world. ${ }^{1}$ It exists as two main histological types, diffuse and intestinal, as described by Laurén, ${ }^{2}$ and is thought to result from a combination of environmental factors and accumulation of specific genetic alterations, and consequently mainly affects older patients. COX-2 is an inducible enzyme and produces prostaglandins in response to various inflammatory stimuli or growth factors. Expression of COX-2 is elevated in gastric

Correspondence: Dr AN Milne, MD, PhD, Department of Pathology, H04-312, University Medical Center Utrecht, Heidelberglaan 100, Postbox 85500, Utrecht 3508 GA, The Netherlands.

E-mail: a.n.a.milne@umcutrecht.nl

Received 07 May 2007; revised 10 September 2007; accepted 19 September 2007; published online 29 February 2008 adenocarcinomas as compared with in the nonneoplastic mucosa, ${ }^{3}$ and is predominantly expressed in intestinal-type gastric carcinomas and its precursor lesions. ${ }^{4,5}$ COX-2 overexpression has been associated with inhibition of apoptosis, ${ }^{6}$ increased metastatic potential ${ }^{7}$ and neoangiogenesis. ${ }^{8}$

Interestingly, we have found previously ${ }^{9}$ that COX-2 expression varies significantly between early-onset gastric cancers (presenting at $\leq 45$ years old) and conventional cancers (presenting >45 years old), with COX-2 overexpression occurring rarely in early-onset gastric cancers. In light of studies showing reduced risk of gastric cancer in non-steroidal anti-inflammatory drug users, ${ }^{10-12}$ our results may have clinical implications, as they suggest that this reduced risk may apply only to gastric cancers in older patients, as COX-2 does not 
appear to play an important role in early-onset gastric cancer. It also implies that genetic changes typical for conventional tumors more readily induce COX-2 expression than those associated with earlyonset gastric cancer. The mechanism behind this difference in COX-2 regulation and expression in these sub-types of gastric cancer is intriguing.

Transcriptional regulation has been shown to be the major mechanism in regulating the expression of COX-2, although posttranscriptional mechanisms such as increased stability of COX-2 mRNA (eg, via HuR) also seem important. ${ }^{9}$ The expression of $C O X-2$ is regulated by a complex signal transduction pathway in which many nuclear proteins interact with the $C O X-2$ promoter region and play a decisive role in gene transcription. ${ }^{13}$ Naturally occurring singlenucleotide polymorphisms (SNPs) in the COX-2 promoter may therefore have a great impact on gene transcriptional activity by altering the binding capability with certain nuclear proteins, resulting in inter-individual variability in susceptibility to cancer and in response to the treatment of patients with COX-2 inhibitors. Indeed, Papafili et a $1^{14}$ have described a polymorphism in the promoter region of $C O X-2$, characterized by a guanine $(\mathrm{G})$ to cytosine (C) transition at position $-765(-765 \mathrm{G}>\mathrm{C})$. This polymorphism appears to disrupt a Stimulatory protein 1 (Sp1)-binding site, which is considered to be a positive activator of transcription and leads to a $30 \%$ reduction of $C O X-2$ promoter activity in vitro ${ }^{14}$ and is also known to be associated with decreased COX-2 expression in the colon. ${ }^{15}$

In this study, we examine the distribution of the COX-2 -765 G>C polymorphism in 241 gastric cancers (including early-onset gastric cancer, conventional gastric cancer and gastric stumps cancers) and 100 control patients using real-time PCR with MGB fluorescent probes and sequence analysis, and investigate the relationship with COX-2 expression in gastric cancer using immunohistochemistry.

\section{Materials and methods}

\section{Patients}

Ninety-six conventional gastric cancer samples ( $>45$ years old), diagnosed between 1993 and
2003, were obtained from the Academic Medical Centre, Amsterdam, together with 30 gastric stump cancer samples from the Amsterdam post-gastrectomy cohort. ${ }^{16}$ One hundred and fifteen cases of gastric carcinoma in patients under 45 years of age, 90\% diagnosed between 1994 and 2002 and 10\% diagnosed between 1980-1994, were obtained from 24 different institutions throughout the Netherlands through the nationwide database system, and from the Department of Pathology at the Jorvi Hospital (Espoo, Finland). The tumors were classified by an experienced gastrointestinal pathologist (GJA Offerhaus) according to the Laurén classification as intestinal, diffuse or mixed gastric adenocarcinomas, as can be seen in Table 1. The control group consisted of 100 DNA samples from healthy men, recruited from the department of endocrinology at the Academic Medical Center, Amsterdam, as published previously. ${ }^{17}$

\section{DNA Isolation}

DNA was isolated from formalin-fixed tissue using the QIAamp DNA Mini kit (Qiagen, Venlo, the Netherlands) or the Puregene DNA Isolation kit (Gentra, MN, USA) according to the manufacturer's instructions. Normal tissue was obtained from a tumor-free lymph node, or where necessary from tissue with a small component of neoplastic cells. DNA concentrations were measured using the NanoDrop spectrophotometer (Isogen Life Science, IJsselstein, the Netherlands).

\section{Real-time PCR}

The polymorphism $765 \mathrm{G}>\mathrm{C}$ in the promoter region of $C O X-2$ was detected using LightCycler 2.0 (Roche, Mannheim, Germany) with 5'-CATTAACTATTTAC AGGGTAACTGCTTAGG- $3^{\prime}$ and $5^{\prime}$-CCCCCTCCTTG TTTCTTGGA-3' (Applied Biosystems, Foster City, USA) as primers and MGB fluorescent probes 6-FAM-5'-CTTTCCCGCCTCTCT- ${ }^{\prime}$ and TET-5'-CTTT CCCCCCTCTCT-3' (Applied Biosystems) in a $20 \mu \mathrm{l}$ reaction mixture containing $10 \mu \mathrm{l}$ of QuantiTect Probe PCR Master Mix (Qiagen, Leusden, the Netherlands), 10 pmol forward and reverse primer,

Table 1 Patient characteristics

\begin{tabular}{|c|c|c|c|}
\hline & No. of patients & Age/range & Histology \\
\hline $\begin{array}{l}\text { Early-onset gastric cancer } \\
\text { (early-onset gastric cancer) }\end{array}$ & 115 & $\leq 45(21-45$ years $)$ & $\begin{array}{l}\text { Intestinal, } 25(22 \%) \\
\text { Diffuse, } 80(70 \%) \\
\text { Mixed, } 10(9 \%)\end{array}$ \\
\hline Conventional gastric cancer & 96 & $>45(47-86$ years $)$ & $\begin{array}{l}\text { Intestinal, } 49(51 \%) \\
\text { Diffuse, } 36(38 \%) \\
\text { Mixed, } 11(11 \%)\end{array}$ \\
\hline Gastric stump cancer (GSC) & 30 & (54-85 years) & $\begin{array}{l}\text { Intestinal, } 26(87 \%) \\
\text { Diffuse, } 2(7 \%) \\
\text { Mixed, } 2(7 \%)\end{array}$ \\
\hline Control group & 100 & (22-52 years) & None \\
\hline
\end{tabular}


2 pmol of each probe and 50 ng genomic DNA. PCR conditions were as follows: $94^{\circ} \mathrm{C}$ for $15 \mathrm{~min}$ followed by 45 cycles at $94^{\circ} \mathrm{C}$ for $15 \mathrm{~s}$ and at $60^{\circ} \mathrm{C}$ for $30 \mathrm{~s}$. In each run, three positive control samples (GG, GC and CC allele), as confirmed by sequencing, were used together with water as a negative control.

\section{Sequencing}

To confirm our result of real-time quantitative PCR, $10 \%$ of the samples were sequenced. The promoter region was amplified using primers 5'-GCATACGTT TTGGACATTTAG-3' (forward) and 5'-CTACCTTCA GTGTACATAGC-3' (reverse) (Applied Biosystems). PCR products were purified using the QIAquick PCR Purification kit (Qiagen) according to the manufacturer's instructions. The sequences were analyzed on an ABI 3100 automated sequencer (Applied Biosystems) using the ABI Big Dye Terminator Cycle
Sequence kit (Applied Biosystems) and the forward internal primer $5^{\prime}$-GTTTTGGACATTTAGCGTCC-3' (Applied Biosystems). Sequences of control samples obtained from the Pathology Department at the Johns Hopkins Medical Institute (Baltimore, USA) were also confirmed by this method.

\section{Immunohistochemistry}

COX-2 immunohistochemistry was carried out on tissue microarrays (TMA) when available $(n=184)$ and as described previously. ${ }^{9}$ In 51 cases, it was performed on whole-tissue sections and in six cases tumor tissue was no longer available or unassessable on the TMA. Sections $(4 \mu \mathrm{m})$ were deparaffinized and antigen was retrieved by $10 \mathrm{~min}$ of boiling in $0.01 \mathrm{M}$ Na-citrate buffer ( $\mathrm{pH}$ 6), followed by immersion in $0.03 \%$ hydrogen peroxide in methanol for $20 \mathrm{~min}$. Non-specific binding sites were blocked
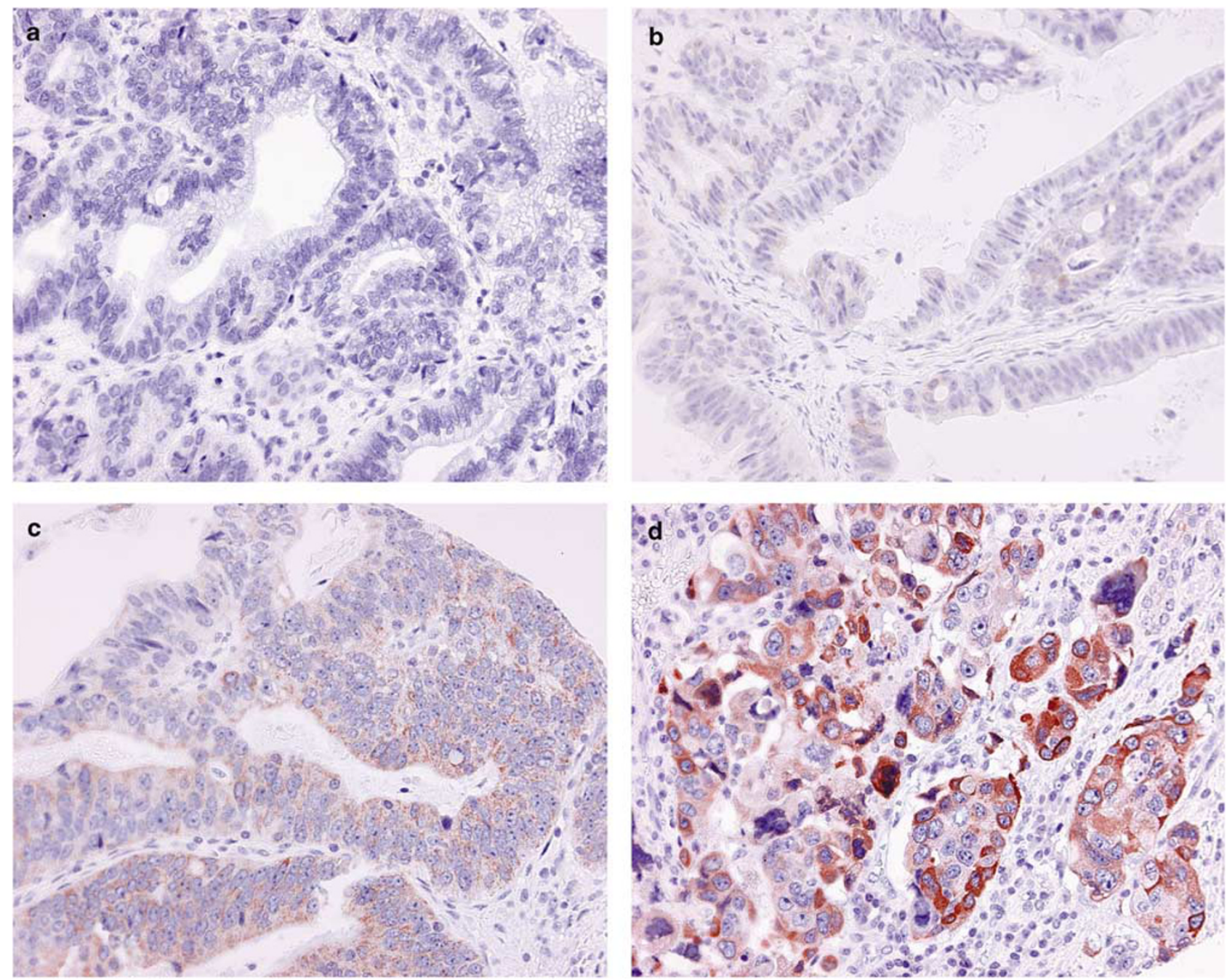

Figure 1 COX-2 immunohistochemistry. (a) Category 0, no staining; (b) category 1, weak diffuse cytoplasmic staining (may contain stronger intensity in less than $10 \%$ of the cancer cells); (c) category 2, moderate to strong granular cytoplasmic staining in 10-50\% of the cancer cells; (d) category $3,>50 \%$ of the tumor cells stained with strong intensity. For statistical analysis, scores 0 and 1 were categorized as COX-2 low and scores 2 and 3 as COX-2 high. 
by preincubation with and $0.01 \mathrm{M}$ Tris, $0.1 \mathrm{M} \mathrm{MgCl}_{2}$, $0.5 \%$ Tween-20, $1 \%$ BSA and 5\% normal goat serum for $1 \mathrm{~h}$. The primary antibody was incubated using monoclonal COX-2 antibody at a dilution of 1:100 (Cayman Chemical Co., Ann Arbor, USA) at $4^{\circ} \mathrm{C}$ overnight. Antibody binding was visualized using the Powervision + poly-HRP detection system (ImmunoVision Technologies, Daly City, CA, USA) with 3,3-amino-9-ethylcarbazole (Sigma-Aldrich, Zwijndrecht, the Netherlands) as chromogen. Sections were counterstained with hematoxylin.

\section{Scoring}

The overall score of the tumor was the highest score found. The following scoring criteria of the tumor cells were used (Figure 1): 0, no staining; 1, weak diffuse cytoplasmic staining (may contain stronger intensity in less than $10 \%$ of the cancer cells); 2 , moderate to strong granular cytoplasmic staining in $10-50 \%$ of the cancer cells; $3,>50 \%$ of the tumor cells stained with strong intensity. Scores 0 and 1 were categorized as 'COX-2 low' and scores 2 and 3 as 'COX-2 high' for statistical analyses. ${ }^{18}$ No slides showed increased negative staining around the edges, and the age of the block had no influence on immunohistochemical staining.

\section{Statistics}

The SPSS 14.0 software package was used for statistical analysis. A $\chi^{2}$-test was applied to the groups of gastric cancer to determine whether there was a statistical difference $(P<0.05)$ between the presence of the $\mathrm{C}$ or $\mathrm{G}$ allele, as well as to examine the correlation between the presence of the $C$ or $G$ allele and COX-2 overexpression. A binary logistic regression model was used to adjust for potential confounding factors such as location (cardia or body in the case of early-onset gastric cancer and conventional gastric cancer) and histological type.

\section{Results}

\section{Distribution of COX-2 - 765 GC Polymorphism}

The distribution of the COX-2 -765 promoter polymorphism was examined in 241 cases of gastric cancer, including 96 conventional gastric cancers, 115 early-onset gastric cancers and 30 gastric stump cancers, as well as in 100 healthy control cases, as can be seen in Table 2. All genotypic distributions were in Hardy-Weinberg equilibrium $(P \geq 0.05)$.

Of note the frequencies of the three genotypes (GG, GC and CC) were similar in early-onset gastric cancer, conventional gastric cancer and stump cancer, with no statistical difference between these gastric cancer groups in a $\chi^{2}$-test. There was a statistically significant difference in the presence of the $\mathrm{C}$ allele in patients with gastric cancer (earlyonset gastric cancer, conventional gastric cancer and gastric stump cancer) compared with the control group $(P=0.007)$, with the $C$ allele associated with protection against gastric cancer.

There was also no association between the presence of any one polymorphism and histological type.

\section{Cox-2 Expression in Gastric Cancer}

Expression of COX-2 was assessed by immunohistochemistry in 235 of the gastric cancer samples, which were subject to polymorphism analysis, including early-onset gastric cancer, conventional gastric cancer and stump cancers, as can be seen in Table 3. Of note, 94 of the early-onset gastric cancers and 90 cases of conventional gastric cancers described in Table 3 have been published previously, ${ }^{9}$ where a statistically significant difference $(P<0.001)$ was seen between early-onset gastric cancer and conventional gastric cancer, with early-onset gastric cancer having a COX-2 lowexpressing phenotype as well as a statistically significant association with the intestinal phenotype $(P<0.001)$. This statistical difference remained

Table 2 Prevalence of $-765 \mathrm{G}>\mathrm{C} C O X-2$ genotype

\begin{tabular}{|c|c|c|c|c|}
\hline$C O X-2-765$ genotype $^{\mathrm{a}}$ & Early-onset gastric cancer & Conventional gastric cancer & Gastric stump cancer & Controls \\
\hline GG & 80/115 (70\%) & 73/96 (76\%) & 23/30 (77\%) & $59(59 \%)$ \\
\hline GC & $33 / 115(29 \%)$ & 19/96 (20\%) & $5 / 30(17 \%)$ & $32(32 \%)$ \\
\hline CC & $2 / 115(2 \%)$ & $4 / 96(4 \%)$ & $2 / 30(7 \%)$ & $9(9 \%)$ \\
\hline Presence of C allele & $30 \%$ & $24 \%$ & $23 \%$ & $41 \%$ \\
\hline
\end{tabular}

${ }^{\mathrm{a}}$ All percentages rounded to the nearest digit.

Table 3 COX-2 expression patterns in gastric cancer

\begin{tabular}{lccr}
\hline Immunohistochemistry & Early-onset gastric cancer & Conventional gastric cancer & Gastric stump cancer \\
\hline COX-low & $95 / 110(86 \%)$ & $29 / 95(31 \%)$ & $12 / 30(40 \%)$ \\
COX-high & $15 / 110(14 \%)$ & $66 / 95(69 \%)$ & $18 / 30(60 \%)$ \\
\hline
\end{tabular}


when adjusted for histology and location using a binary logistic regression model $(P<0.001)$. They have been included here for comparison with the gastric stump cancers and for the association with COX-2 -765 polymorphism.

We found that the COX-2 expression profile of gastric stump cancers bears similarity to that of conventional gastric cancers, with no statistical difference between these two groups $(P=0.25)$, and thus the early-onset gastric cancer group remained significantly different from gastric stump and conventional gastric cancers with respect to COX-2 expression $(P<0.001)$. There was no significant correlation between $C O X-2$ expression and -765 genotype $(P=0.22)$.

\section{Discussion}

The diseases in which a role for COX-2 has been shown are usually characterized by varying individual and even ethnic susceptibility, implying the role of genetic factors. ${ }^{19}$ The specific function of COX-2 in the formation of prostaglandins makes it a strong candidate for increasing susceptibility to common cancers. Genetic polymorphisms altering the level of protein expressed would be anticipated to have a substantial influence on disease activity. Several SNPs in COX-2 have been reported previously, but many of these polymorphisms seem to be functionally insignificant and not associated with susceptibility to cancer. ${ }^{20-22}$

However, it has been shown that the $-765 \mathrm{G}>\mathrm{C}$ $C O X-2$ polymorphism has been reported to disrupt an Sp1-binding site and displays a lower promoter activity, ${ }^{14}$ and interestingly, a higher COX-2 expression has been found in the normal mucosa of patients with FAP who carried the -765GG polymorphism, ${ }^{15}$ than carriers of the $\mathrm{C}$ allele. These findings awaken curiosity within the field of gastric cancer, as to whether it may also play a role here.

In this study, we sought to identify the distribution of the $-765 \mathrm{G}>\mathrm{C}$ polymorphism in the promoter of the human $C O X-2$ gene in early-onset gastric cancer, conventional gastric cancer and gastric stump cancers. In addition, we looked at the effect of this polymorphism on COX-2 expression. We found that the $\mathrm{G}$ allele was associated with gastric cancer, including early-onset gastric cancer, conventional gastric cancer and gastric stump cancers, with the $\mathrm{C}$ allele showing a protective effect, and there was no significant difference between histological types. In addition, we found no correlation between the presence of the $G$ allele and overexpression of the COX-2 protein in either gastric cancer or normal mucosa.

An association between the $765 \mathrm{C}$ allele and increased risk of esophageal squamous cell carcinoma has been demonstrated previously, ${ }^{23}$ and an increased risk of colon cancer in Singapore Chinese who consume high amounts of n-6 polyunsaturated fatty acids has also been associated with this polymorphism. ${ }^{24}$ However, a study in Japan showed no association between the $-765 \mathrm{G}>\mathrm{C}$ polymorphism and risk of colorectal cancer. ${ }^{25}$ The role of this polymorphism in gastric cancer has been variable and the literature is inconclusive. Liu et $a l^{26}$ found that subjects carrying the 1195AA genotype, another COX-2 promoter polymorphism, had an increased risk of gastric cancer and a significant increase in COX-2 expression; however, they failed to show any association with the $-765 \mathrm{G}>\mathrm{C}$ polymorphism and gastric cancer. This may be due the fact that the variant genotypes (CC) of the $-765 \mathrm{G}>\mathrm{C}$ polymorphism were rare in the population of their study $(<1 \%)$, whereas in our study group, we saw the CC genotype in $9 \%$ of our control group (which consisted of 100 healthy males as described previously; Westerveld et al ${ }^{17}$ ). Additional controversy in the literature lies with a study by Pereira et al, ${ }^{27}$ where an association with the $\mathrm{C}$ allele and gastric cancer was reported. This is unexpected, as the described decrease in expression has been reported in association with the C allele. ${ }^{14,15}$ One would thus expect that the $\mathrm{G}$ allele, is responsible for conferring an increased susceptibly to gastric cancer. However, contrary to the study by Brosens et al where they found a correlation between COX-2 expression in the normal mucosa and the -765 polymorphism, we find no relationship between the $-765 C O X-2$ polymorphism and expression in either the tumor or normal tissue, and thus the situation in the stomach does not appear to mirror that in the intestine in this regard. However, despite showing an association with the $\mathrm{C}$ allele and gastric cancer, Pereira et al also describe that their results revealed a possible protective role for $-765 \mathrm{C}$ carriers, a finding that is confirmed with statistical significance in our current study. Previous studies have shown that SNPs in the COX-2 gene vary greatly in different ethnic populations, ${ }^{14,15}$ providing a possible explanation for the discrepancy within the literature in relation to gastric cancer.

In summary, we show that the COX-2 -765 $\mathrm{G}$ allele promoter polymorphism is significantly associated with gastric cancer, including early-onset gastric cancer, conventional gastric cancers and gastric stump cancer, when compared with the normal control group, but does not appear to be related directly to COX-2 expression patterns in the stomach. Although early-onset gastric cancers appear to have a unique COX-2 expression pattern when compared with conventional gastric cancer, the exact mechanism by which this occurs is yet to be elucidated.

\section{Acknowledgement}

We thank Dr Michael Goggins at the Pathology Department at the Johns Hopkins Medical Institute (Baltimore, USA) for kindly providing control 
samples. We also thank Sjoerd Repping at the Endocrinology Department, Academic Medical Centre, Amsterdam, for providing the control group, and Professor Penti Sipponen for supplying the gastric cancer samples from Finland. Robert Sitarz, the first author, was funded by the Stella Major Foundation.

\section{References}

1 Pisani P, Parkin DM, Bray F, et al. Estimates of the worldwide mortality from 25 cancers in 1990. Int J Cancer 1999;83:18-29.

2 Laurén P. The two histological main types of gastric carcinoma: diffuse and so-called intestinal-type carcinoma. An attempt at a histo-clinical classification. Acta Pathol Microbiol Scand 1965;64:31-49.

3 Ristimaki A, Honkanen N, Jankala H, et al. Expression of cyclooxygenase-2 in human gastric carcinoma. Cancer Res 1997;57:1276-1280.

4 Saukkonen K, Nieminen O, van Rees B, et al. Expression of cyclooxygenase-2 in dysplasia of the stomach and in intestinal-type gastric adenocarcinoma. Clin Cancer Res 2001;7:1923-1931.

5 van Rees BP, Saukkonen K, Ristimaki A, et al. Cyclooxygenase-2 expression during carcinogenesis in the human stomach. J Pathol 2002;196:171-179.

6 Souza RF, Shewmake K, Beer DG, et al. Selective inhibition of cyclooxygenase-2 suppresses growth and induces apoptosis in human esophageal adenocarcinoma cells. Cancer Res 2000;60:5767-5772.

7 Nithipatikom K, Isbell MA, Lindholm PF, et al. Requirement of cyclooxygenase-2 expression and prostaglandins for human prostate cancer cell invasion. Clin Exp Metastasis 2002;19:593-601.

8 Tsujii M, Kawano S, Tsuji S, et al. Cyclooxygenase regulates angiogenesis induced by colon cancer cells. Cell 1998;93:705-716.

9 Milne AN, Carvalho R, Morsink FM, et al. Early-onset gastric cancers have a different molecular expression profile than conventional gastric cancers. Mod Pathol 2006;19:564-572.

$10 \mathrm{Hu}$ PJ, Yu J, Zeng ZR, et al. Chemoprevention of gastric cancer by celecoxib in rats. Gut 2004;53:195-200.

11 Langman MJ, Cheng KK, Gilman EA, et al. Effect of anti-inflammatory drugs on overall risk of common cancer: case-control study in general practice research database. BMJ 2000;320:1642-1646.

12 Akre K, Ekstrom AM, Signorello LB, et al. Aspirin and risk for gastric cancer: a population-based case-control study in Sweden. Br J Cancer 2001;84:965-968.

13 Dixon DA. Regulation of COX-2 expression in human cancers. Prog Exp Tumor Res 2003;37:52-71.

14 Papafili A, Hill MR, Brull DJ, et al. Common promoter variant in cyclooxygenase-2 represses gene expression: evidence of role in acute-phase inflammatory response. Arterioscler Thromb Vasc Biol 2002;22:1631-1636.
15 Brosens LA, Iacobuzio-Donahue CA, Keller JJ, et al. Increased cyclooxygenase-2 expression in duodenal compared with colonic tissues in familial adenomatous polyposis and relationship to the $-765 \mathrm{G} \rightarrow \mathrm{C}$ COX-2 polymorphism. Clin Cancer Res 2005;11: 4090-4096.

16 Tersmette AC, Offerhaus GJ, Giardiello FM, et al. Longterm prognosis after partial gastrectomy for benign conditions. Survival and smoking-related death of 2633 Amsterdam postgastrectomy patients followed up since surgery between 1931 and 1960. Gastroenterology 1991;101:148-153.

17 Westerveld H, Visser L, Tanck M, et al. CAG repeat length variation in the androgen receptor is not associated with spermatogenic failure. Fertil Steril 2008;89:253-259.

18 Buskens CJ, Van Rees BP, Sivula A, et al. Prognostic significance of elevated cyclooxygenase 2 expression in patients with adenocarcinoma of the esophagus. Gastroenterology 2002;122:1800-1807.

19 Cipollone F, Toniato E, Martinotti S, et al. A polymorphism in the cyclooxygenase 2 gene as an inherited protective factor against myocardial infarction and stroke. JAMA 2004;291:2221-2228.

20 Fritsche E, Baek SJ, King LM, et al. Functional characterization of cyclooxygenase-2 polymorphisms. J Pharmacol Exp Ther 2001;299:468-476.

21 Humar B, Giovanoli O, Wolf A, et al. Germline alterations in the cyclooxygenase-2 gene are not associated with the development of extracolonic manifestations in a large Swiss familial adenomatous polyposis kindred. Int J Cancer 2000;87:812-817.

22 Spirio LN, Dixon DA, Robertson J, et al. The inducible prostaglandin biosynthetic enzyme, cyclooxygenase 2 , is not mutated in patients with attenuated adenomatous polyposis coli. Cancer Res 1998;58:4909-4912.

23 Zhang X, Miao X, Tan W, et al. Identification of functional genetic variants in cyclooxygenase-2 and their association with risk of esophageal cancer. Gastroenterology 2005;129:565-576.

24 Koh WP, Yuan JM, van den Berg D, et al. Interaction between cyclooxygenase-2 gene polymorphism and dietary $n-6$ polyunsaturated fatty acids on colon cancer risk: the Singapore Chinese Health Study. Br J Cancer 2004;90:1760-1764.

25 Hamajima N, Takezaki T, Matsuo K, et al. Genotype frequencies of cyclooxygenease 2 (COX2) rare polymorphisms for Japanese with and without colorectal cancer. Asian Pac J Cancer Prev 2001;2:57-62.

26 Liu F, Pan K, Zhang X, et al. Genetic variants in cyclooxygenase-2: expression and risk of gastric cancer and its precursors in a Chinese population. Gastroenterology 2006;130:1975-1984.

27 Pereira C, Sousa H, Ferreira P, et al. 765G > C COX-2 polymorphism may be a susceptibility marker for gastric adenocarcinoma in patients with atrophy or intestinal metaplasia. World J Gastroenterol 2006;12: 5473-5478. 